\title{
Quantification of relative afferent pupillary defects induced by posterior sub-Tenon's, peribulbar, and retrobulbar anaesthetics
}

\author{
Andrew S Ramsay, Neeta Ray-Chaudhuri, Margaret Dayan, David Walshaw
}

\begin{abstract}
Aims-The effect of local anaesthetics on optic nerve function can be investigated by quantifying the relative afferent pupillary defect (RAPD).

Methods-The study compared the depth of induced RAPD following posterior subTenon's, retrobulbar, and peribulbar local anaesthetics using crossed polarising filters before cataract surgery (time $1=5$ minutes), immediately after surgery (time $2=42$ minutes (av)), and once again on the ward (time $3=107$ minutes (av)).

Results-All patients developed a RAPD. There was no significant difference in the depth of RAPD between the groups at any one time period. The peribulbar group had a significantly steeper decay in RAPD from time 1 to time $2(p=0.014)$. This effect was reduced when the shorter operation time for this group was entered as a cofactor $(p=0.063)$. By time 3 the RAPDs for all groups had decayed similarly so that no differences could be detected.

Conclusion-All three anaesthetic methods caused a similar level of disruption to optic nerve conduction immediately following administration and at the time of day case discharge.
\end{abstract}

(Br f Ophthalmol 2001;85:1445-1446)

Local anaesthetics delivered within the orbit are known to impair optic nerve conduction. ${ }^{1-3}$ This study measured the degree to which three local anaesthetic techniques attenuated optic nerve conduction by quantifying induced RAPDs by a crossed polarising filter technique. ${ }^{45}$

Optic nerve function following peribulbar and retrobulbar anaesthesia has been investigated in terms of visual evoked potentials ${ }^{3}$ and visual function. ${ }^{12}$ Posterior sub-Tenon's anaesthesia is a newer technique that has been less extensively investigated. ${ }^{67}$ Although RAPDs have been recorded following local anaesthet$\operatorname{ics}^{12}$ they have not been quantified. This study measured the effect of these three local anaesthetic techniques on RAPD using crossed polarising filters. This method is simple, quick, reproducible and, in contrast with neutral density filters, has a continuous scale of measurement. ${ }^{4}$

Materials and methods

Sixty consecutive patients undergoing phacoemulsification were randomly allocated to one of the three anaesthetic groups. Subjects with pre-existing RAPDs or other ocular disease were excluded.

Each of the three standardised anaesthetic techniques was performed by a single ophthalmologist. A standard anaesthetic cocktail of 750 units of hyaluronidase in $7 \mathrm{ml} 2 \%$ lignocaine was used. The posterior subTenon's technique involved delivering $3.5 \mathrm{ml}$ through an inferomedial conjunctivo-episcleral buttonhole via a blunt, curved, sub-Tenon's cannula passed posteriorly around the globe. The peribulbar group received $7.5 \mathrm{ml}$ via two injections with a $40 \mathrm{~mm}$ needle directed parallel to the bony orbit along the inferolateral orbital floor and below the trochlear notch. Retrobulbar injections of $3.5 \mathrm{ml}$ of the mixture were performed using a $38 \mathrm{~mm}$ retrobulbar needle directed within the muscle cone.

RAPD measurement was performed using an indirect ophthalmoscope light under dim background illumination using a standardised technique. ${ }^{8}$

Quantification of the pupil defect was achieved by attenuating the light to the unaffected pupil by rotating a polarising filter against another until the defect was neutralised using a reverse testing technique. ${ }^{4}$ RAPD measurement was performed preoperatively, 5 minutes after local anaesthetic administration (time 1), immediately postoperatively (time 2), and finally back on the ward (time 3 ).

Degrees of rotation of the crossed polarising filters were converted to neutral density filter $\log$ units. ${ }^{4}$ Results were analysed using paired and unpaired Student's $t$ tests and analysis of variance.

\section{Results}

All patients developed an RAPD by 5 minutes. All anaesthetics were reported by surgeon and patient to have given satisfactory anaesthesia and akinesia.

There were no significant intergroup differences in the mean RAPD, which lightened with time (Table 1, Fig 1). There was a significant decay in RAPD from time 1 to 2 for all groups $(p<0.001)$, and a significant difference in the rates of decay between the three anaesthetic types $(p=0.014)$ with the peribulbar group lightening fastest. Analysis of covariance revealed the level of decay was related to the amount of time elapsed ( $\mathrm{p}=0.03)$. However, when operation time was also included as a covariate, there was no significant relation between anaesthetic type and attenuation of RAPD ( $p=0.278)$. By time 3 the RAPD had decayed so that no significant effects could be detected with respect to time of measurement, operation time, or anaesthetic type. 
Table 1 Mean depth of RAPD (log units) for sub-Tenon's, peribulbar, and retrobulbar anaesthesia at times 1, 2, and 3 (mean (SD))

\begin{tabular}{lllll}
\hline Anaesthetic & $\begin{array}{l}\text { Time 1 } \\
\text { (5 minutes) }\end{array}$ & $\begin{array}{l}\text { Time 2 } \\
\text { (42 (10) minutes) }\end{array}$ & $\begin{array}{l}\text { Time 3 } \\
(107(20) \text { minutes) })\end{array}$ & $\begin{array}{l}\text { Average operation } \\
\text { time (minutes) }\end{array}$ \\
\hline Sub-Tenon's & $2.03(0.5)$ & $1.73(0.40)$ & $1.17(0.46)$ & 27 \\
Peribulbar & $2.11(0.85)$ & $1.49(0.83)$ & $0.93(0.26)$ & 26 \\
Retrobulbar & $2.16(0.51)$ & $1.77(0.71)$ & $1.26(0.75)$ & 27 \\
\hline
\end{tabular}

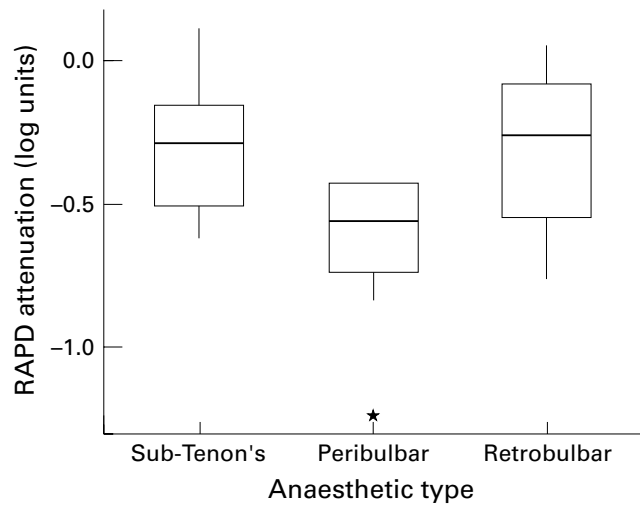

Figure 1 Attenuation of RAPD (measured with crossed polarising filters) with time following administration of sub-Tenon's, peribulbar, and retrobulbar anaesthetics.

No RAPD was detected in two peribulbar subjects at time 2 and three at time 3 , while 2 retrobulbar patients still had (temporary) defects at 18 hours.

\section{Discussion}

Posterior sub-Tenon's, peribulbar, and retrobulbar anaesthetics reliably produced RAPDs in all subjects to a similar speed of onset and depth. Previous studies found RAPDs in only $31 \%$ following retrobulbar anaesthesia ${ }^{2}$ and $85 \%$ after peribulbar anaesthetics. ${ }^{1}$ The extent to which posterior sub-Tenon's anaesthesia produces a RAPD has not been previously investigated to our knowledge.

These differences may be due to nonstandardised clinical methodologies which affect the sensitivity of RAPD testing. ${ }^{8}$

RAPD testing, performed in a systematic manner, is one of a number of methods of investigation of local anaesthesia which include perioperative vision, ${ }^{1}{ }^{2}$ analgesia, ${ }^{7}$ akinesia, ${ }^{1-3} 7$ visual evoked potentials. ${ }^{9}$ Assessment of RAPD with crossed polarising filters ${ }^{45}$ is a simple, quick, and reproducible alternative to neutral density filters ${ }^{4}$ and clinical grading. ${ }^{10}$

There is disagreement as to whether peribulbar $^{1}$ or retrobulbar ${ }^{9}$ anaesthesia has a more profound effect on optic nerve conduction when reduction in vision is used as an indicator. However, in our study there was no significant difference between the depth of RAPD caused by the three methods at any one time point. This is in keeping with the clinical impression that all three techniques can provide adequate, reliable anaesthetics and with a CT study which demonstrated rapid diffusion of contrast labelled anaesthetic throughout the orbit from point of injection. ${ }^{3}$ Our peribulbar technique delivered twice the volume of anaesthetic but this did not increase the depth or duration of the RAPD. ${ }^{1}$

RAPD appeared to recover more quickly initially following peribulbar anaesthesia $(\mathrm{p}=$ 0.014 (time 1-2)) (Fig 1). Also, two patients had temporary, residual RAPDs up to 18 hours after retrobulbar anaesthetics. However, the longer exposure to the microscope light for the sub-Tenon's and retrobulbar groups may have prolonged RAPD depression by retinal bleaching. When operation time was entered as a covariant it was found to have a significant effect on the depth of the postoperative RAPD ( $p=$ 0.031), reducing the difference between the anaesthetic groups' RAPD decay to $p=0.063$. It would be interesting to compare these results with pupil changes after phacoemulsification after topical anaesthesia which was not practised in this unit at the time. The degree of pupillary dilatation may also influence RAPD by increasing retinal bleaching.

As the offset of RAPD was similar for all anaesthetic types no one method could be said to allow better vision for the patients' journey home.

Disclaimer: The authors have no financial interest in any product named in this paper.

1 Talks SJ, Chong NH, Gibson JM, et al. Visual acuity and pupillary reactions after peribulbar anaesthesia [see comments]. Br f Ophthalmol 1994;78:41-3.

2 Levin ML, O'Connor PS. Visual acuity after retrobulbar anesthesia. Ann Ophthalmol 1989;21:337-9.

3 Ropo A, Nikki P, Ruusuvara P, et al. Comparison of retrobulbar and periocular injections of lignocaine by computerised tomography. Br F Ophthalmol 1991;75:417-20.

4 Ramsay A, Williamson TH, Parks S, et al. Crossed polarising filters to measure relative afferent pupillary defects: reproducibility, correlation with neutral density filters and use in central retinal vein occlusion. Eye 1995;9 ( Pt 5):624-8.

5 Rosenberg ML, Oliva A. The use of crossed polarized filters in the measurement of the relative afferent pupillary defect. Am f Ophthalmol 1990;110:62-5.

6 Guise PA. Single quadrant sub-Tenon's block. Evaluation of a new local anaesthetic technique for eye surgery. Anaesth Intensive Care 1996;24:241-4.

7 Buys YM, Graham ET. Prospective study of sub-Tenon's versus retrobulbar anaesthesia for inpatient and day-
surgery trabeculectomy. Ophthalmology 1993;100:1585-9.

8 Thompson HS, Corbett JJ, Cox TA. How to measure the RAPD. Surv Ophthalmol 1981;26:39-42.

9 Ropo A, Ruusuvaara P, Setala K. Visual evoked potentials after retrobulbar or periocular anaesthesia. Br F Ophthalmol 1992;76:541-4

10 Bell RA, Waggoner PM, Boyd WM, et al. Clinical grading of relative afferent pupillary defects. Arch Ophthalmol 1993; 111: $938-42$. 